\title{
PROPOSED PROTOTYPE MODEL OF QR CODE INTEGRATION IN UNDERGROUND MINING INDUSTRY USING SMARTPHONES
}

\author{
Vancho Adjiski $^{1}$, Dalibor Serafimovski ${ }^{2}$, Zoran Despodov ${ }^{1}$, Stojance Mijalkovski ${ }^{1}$
}

Received: April 5, 2018

Accepted: April 23, 2018

\begin{abstract}
In today's world, the exponential growth in technological advancements has allowed us to access information much faster and in a more convenient manner than ever before. On daily basis, consumers connect to the digital world through their smartphone devices in a variety of different methods. One of these methods is through QR codes which have become increasingly popular and effective in a variety of different industries. The underground mining industry needs the introduction of modern innovations that would facilitate the flow of information as well as increase the safety at work. There are many practical ways that QR codes can be used in underground mining industry. This paper presents a system of QR code integration in underground mining industry using smartphones, were each worker can receive information and data that are crucial for the successful performance of their work activities. Three scenarios for the application and integration of this system in the mines for underground exploitation will also be presented in this paper.
\end{abstract}

Keywords: QR codes; smartphone; system; integration; data; underground mining

\section{INTRODUCTION}

QR code, which stands for "Quick Response", is a type of matrix barcode, first designed for the automotive industry in Japan (Okazaki et al., 2013). A barcode is a machinereadable optical label that contains information about the item to which it is attached and is readable using smartphones or webcams. The purpose of the QR code is to act as a hyperlink that connects the physical world to the digital world through your smartphone (Pandya and Galiyawala, 2014). With the exponential growth of technology, QR code has a wide range of applications, especially in the mining industry. QR code system can hold large amount of data with fast response time and the use of smartphones among all age groups made accessing QR code very easy by providing the end-user content, including item identification, personal details, time tracking, document management, etc. (Vongpradhip, 2013).

The main advantage of the QR codes is that they are quick, cheap, and easy to employ. $\mathrm{QR}$ codes are computer generated and can be displayed in prints or on screens without

\footnotetext{
${ }^{1}$ Faculty of natural and technical sciences, Mining engineering, "Goce Delchev" University, P.O. box 201, 2000 Shtip, Macedonia

${ }^{2}$ Faculty of electrical engineering, "Goce Delchev" University, P.O. box 201, 2000 Shtip, Macedonia Emails: $\quad$ vanco.adziski@ugd.edu.mk; $\quad$ dalibor.serafimovski@ugd.edu.mk; $\quad$ zoran.despodov@ugd.edu.mk; stojance.mijalkovski@ugd.edu.mk
} 
any specific manufacturing processes. Users with a smartphone having a camera equipped with the correct reader application can scan the image of the QR code to display the end-user content that can include text, video, web page, etc. (Law and So, 2010).

Unlike the traditional 1D bar code which stores data only in its length, QR codes store data in length and height which gives them a much bigger data capacity than is the case with $1 \mathrm{D}$ bar code. QR codes are in ISO/IEC 18004, which means that their specifications are open to the public all over the world through the International Organization for Standardization (Masalha and Hirzallah, 2014).

The QR codes can store up to 7089 numeric characters, 4296 alphanumeric characters, 2953 binary bytes or a mixture of these, or they can connect with the Internet or with databases containing large amounts of data (Vongpradhip, 2013).

Smartphones equipped with sensors, GPS and internet, enable engineers to increase work efficiency, create strategies for innovation, increase productivity, process management and provide an effective way of data collection (Sharma and Dheeraj, 2014; Wagner et al., 2014). To avoid disadvantages between business needs and IT solutions, there is a need for constant communication between engineers and IT experts (Schobel et al., 2014). Therefore, we have created an adaptable prototype model based on a previous analysis of the possibilities of combining mining and IT technologies. Figure 1 shows the possibilities for using QR codes in mining industry.

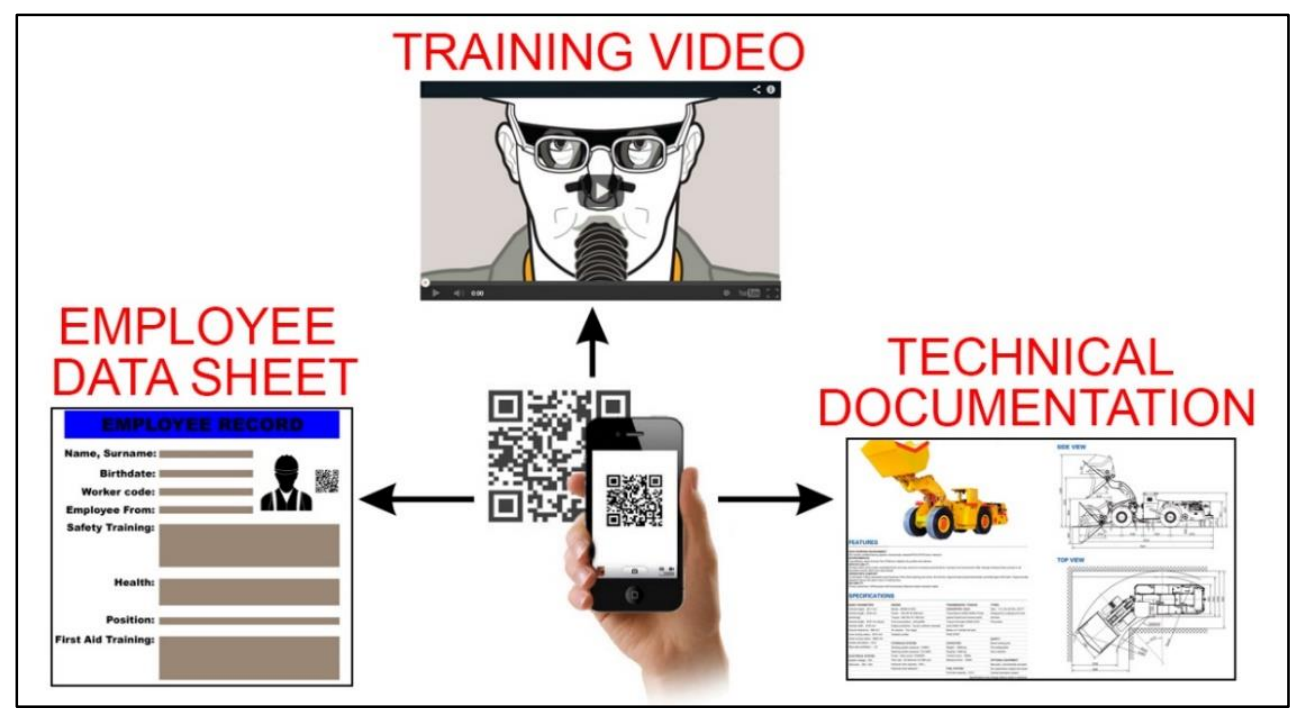

Figure 1 Possibilities for using QR codes in mining industry 


\section{USAGE OF QR CODES IN THE ENGINEERING INDUSTRY}

Not surprisingly, QR codes are primarily being used by marketing companies but the functionality of QR codes is so versatile that they have been used by a great number of people, and the list only continues to grow and expand across a number of industries $(\mathrm{Gu}$ and Sun, 2013). QR codes are not just a tool for marketing purposes, they can be used by anyone wanting to efficiently receive, transmit, access, or share data in a number of forms (Vazquez-Briseno et al., 2010).

Engineering industry professionals have found innovative uses of QR codes in their daily work. Contractors, architects, engineers and developers are all using QR codes to improve productivity (Lorenzo et al., 2014). Here are some ways in which engineering industry professionals are using QR codes to do their daily jobs more efficiently:

- QR codes placed on packaging of building materials to provide more detailed instructions for installation and assembly,

- QR codes placed on signs at job sites which can include safety procedures and full contact information by auto-dialing emergency phone numbers,

- QR codes placed at the proposed construction site that link to web pages or blog posts where concerned citizens can read details about the proposed project,

- QR codes that provide contractors to look at project samples and gain access to the necessary information.

\section{METHODS}

\subsection{Methodology for integration of QR code in underground mining industry}

The methodology that will be presented in this paper for QR code integration in underground mining industry using smartphones consists of the steps presented in Figure 2.

The first step is to define the boundaries of the system, which in this case is the implementation and integration of $\mathrm{QR}$ codes in the mines for underground exploitation.

The second step in this methodology is the development of computer/smartphone application that can be installed on any smartphone device. This computer/smartphone application must be associated with a database that will automatically be updated with new data at a time when the smartphone device is connected to a wireless network.

The third step is the development of a database that will contain all the necessary data and information needed by the miners inside the mine.

Because most mines for underground exploitation are limited in the wireless communication field and the wireless information flow inside the mine, this methodology proposes a simpler and cheaper system, which is installing a WI-FI device 
outside the mine at the entrance point. The fourth step in this methodology consists of installing a hot spot WI-FI outside of the mine where all mining workers will be able to update the data contained in the database by simply using the smartphone application.

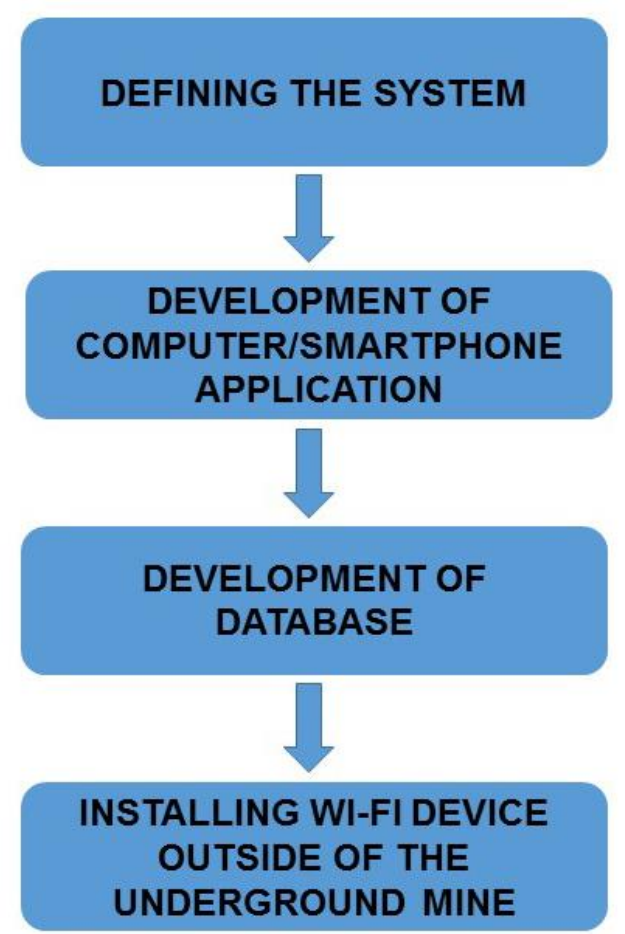

Figure 2 Steps for implementation of the methodology for QR code integration in underground mining industry using smartphones

\subsection{Design of the proposed model}

The proposed model in this paper is based on a pre-comprehensive literature research and analysis of the capabilities of mobile devices to work with data on the go and to facilitate and automate the processes. The proposed model consists of three parts.

The first part is a cross-platform desktop application designed to manage the entire system.

The second part is a cross-platform mobile application designed for all existing mobile platforms with an emphasis on iOS and Android mobile platforms.

The third part of the proposed prototype model is represented by a cloud-based infrastructure that serves the whole data system. It is important to mention that the crossplatform approach we propose in this paper allows the system to run in the existing IT 
infrastructure and technical equipment in the mines without the need for additional investment. The proposed model is fully functional - technically adapted to all operating systems and platforms equally. Figure 3 visually represents the proposed cloud solution of the model.

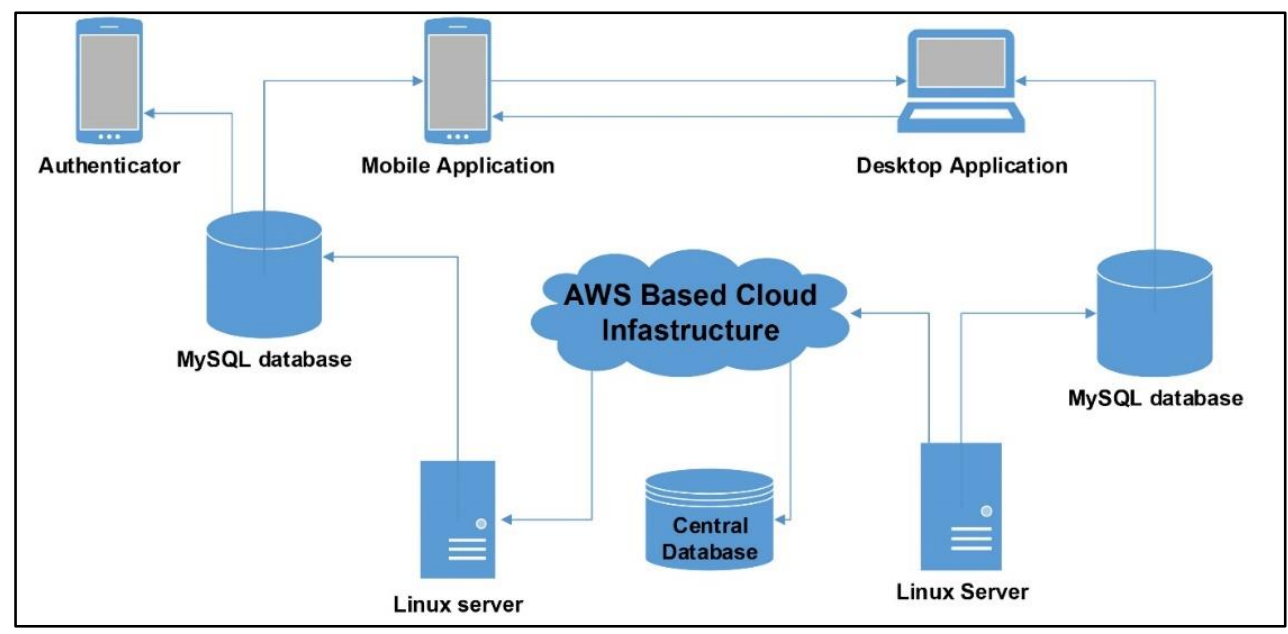

Figure 3 Visual representation of the proposed model

\subsubsection{Desktop application}

The first part of the proposed model consists of a cross-platform oriented desktop application. The application consists of 3 separate modules, the module for generating QR codes, the management module and the statistical module.

QR code creation module (Figure 4). Using this module, the administrator generates $\mathrm{QR}$ codes according to the needs of the mine. All generated codes are written in the central database, and after creation the code is ready for use.

Management module (Figure 4). This module takes a central place in this proposed model prototype. Using this module, the user is able to administer the system by entering data, monitoring the daily activities and monitoring the data arriving from mobile devices in real time. When registering a new employee for using the system, the IMEI code of the mobile device that the employee uses to connect to the system is mandatory. After registration of the mobile device in the system, the mobile application data on that mobile device becomes available to the system. 


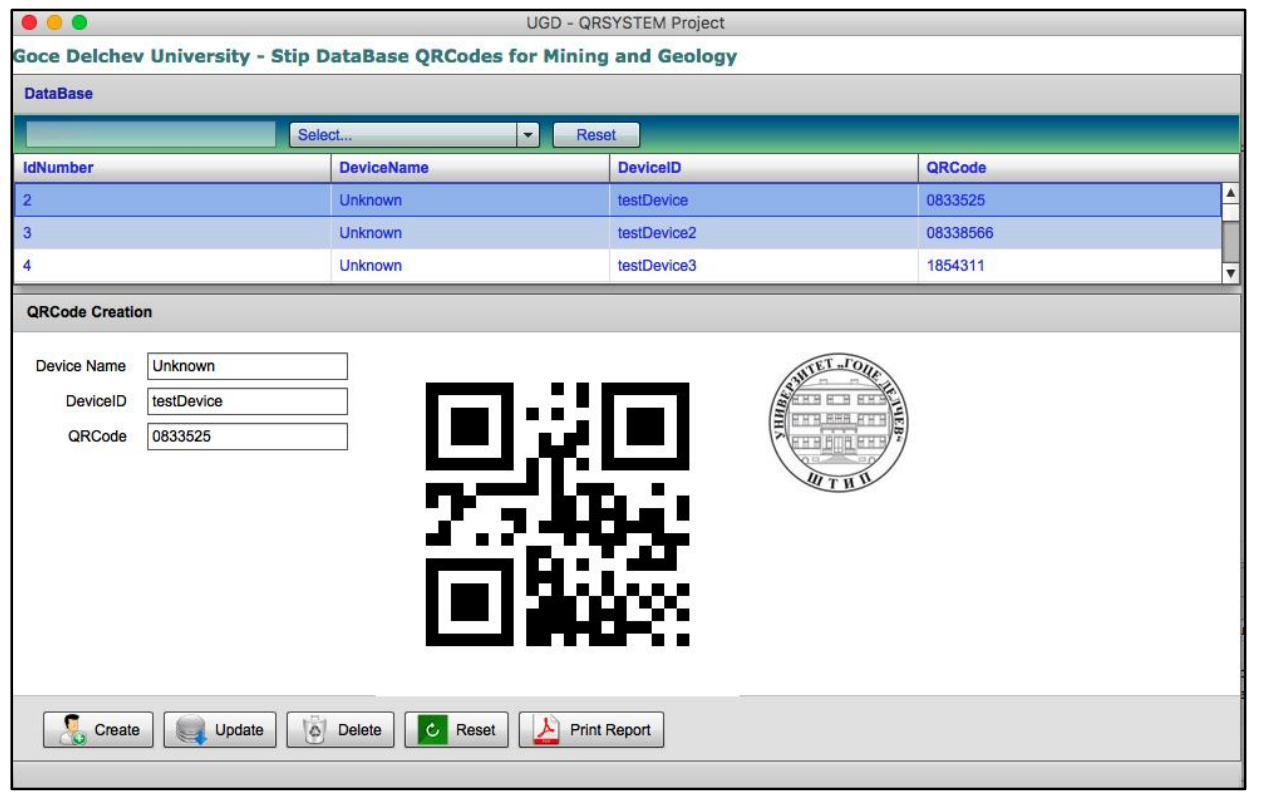

Figure 4 QR code Creation and management module

Statistics module (Figure 5). This module is conceived as a module that generates reports on the overall use of the system. This module includes built-in programmable functionality for automatic creation based on the received data from the mobile application. The user can save the generated feeds in PDF. The statistical module enables monitoring the physical workload of the worker by measuring past steps and lost calories during the working day with the help of built-in sensors in mobile devices that automatically monitor these data (Case et al., 2015).

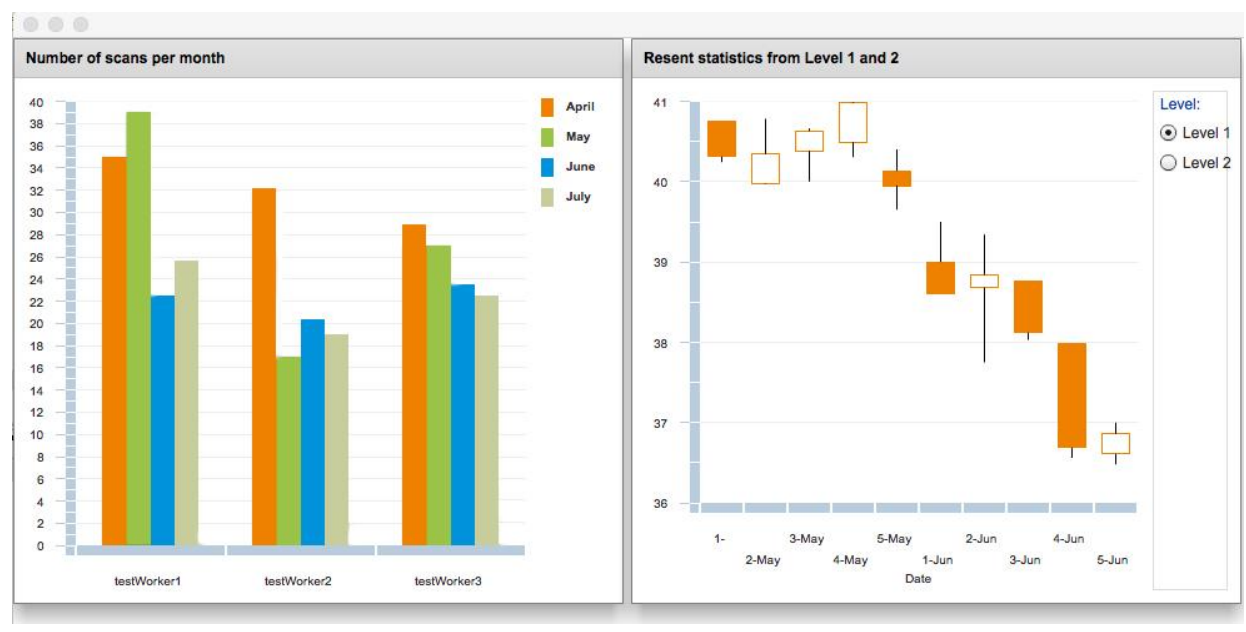

Figure 5 Statistics module 


\subsubsection{Smartphone application}

The main advantage of mobile applications and their usage as real-time data tools is their high personalization and the ability they offer to constantly monitor the time and location of the device and transfer data to a server (Dehlinger and Dixon, 2011; Laurila et al., 2012).

The second part of the proposed prototype model represents a cross-platform mobile application. To use the application inside the working environment, the user needs to be logged into the system and registered with the IMEI code of the used mobile device. Using the built-in QR code recognition module, the user has the ability to scan a certain QR code and retrieve information from the system. The mobile application is divided into several sections depending on the hierarchical placement of the employee who uses it. In the first hierarchical position, employees can only read data on their mobile device from the central database. Employees in the second hierarchical position can also record database data using the mobile application and feed the system with data for generating reports. In addition, in order to increase security, an employee authentication application has been developed. Before using the mobile application, it is necessary for the employee to login using the pin generated by the authentication application. The authentication app serves only during active working hours of the user. In this way, the company is protected against the outflow of confidential data from mobile devices outside working hours. After the end of active working hours the application is practically non-functional until the next working day. Figure 6 shows the visual representation of the solution for an active working session.

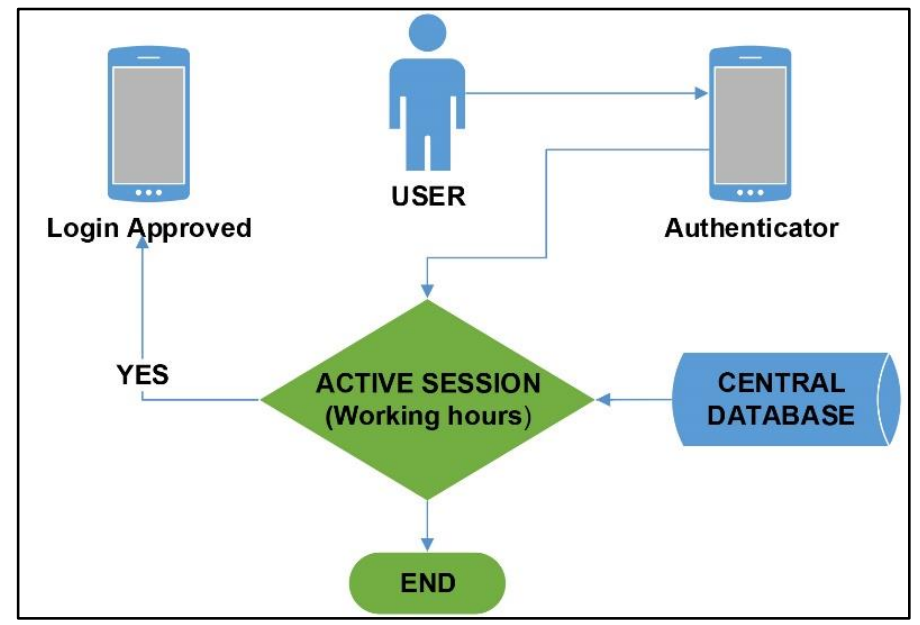

Figure 6 Visual representation of the proposed solution for an active working session 


\subsection{Setting up the system for integrating QR codes in underground mining industry}

The development of the computer/smartphone application with the database is followed by the installation of the application to the smartphone devices that will be used inside the mine. Due to the implemented method in this system, the update of the database will be executed after the workers leave or enter the mine, that is, on the placed hot spot with the installed WI-FI network device. This system with an external update of the database is set due to low cost. The underground mines that can set up an internal communication system where wireless WI-FI devices can be installed in certain places can significantly improve this work methodology. Figure 7 shows the proposed system for integrating QR codes in underground mining industry.

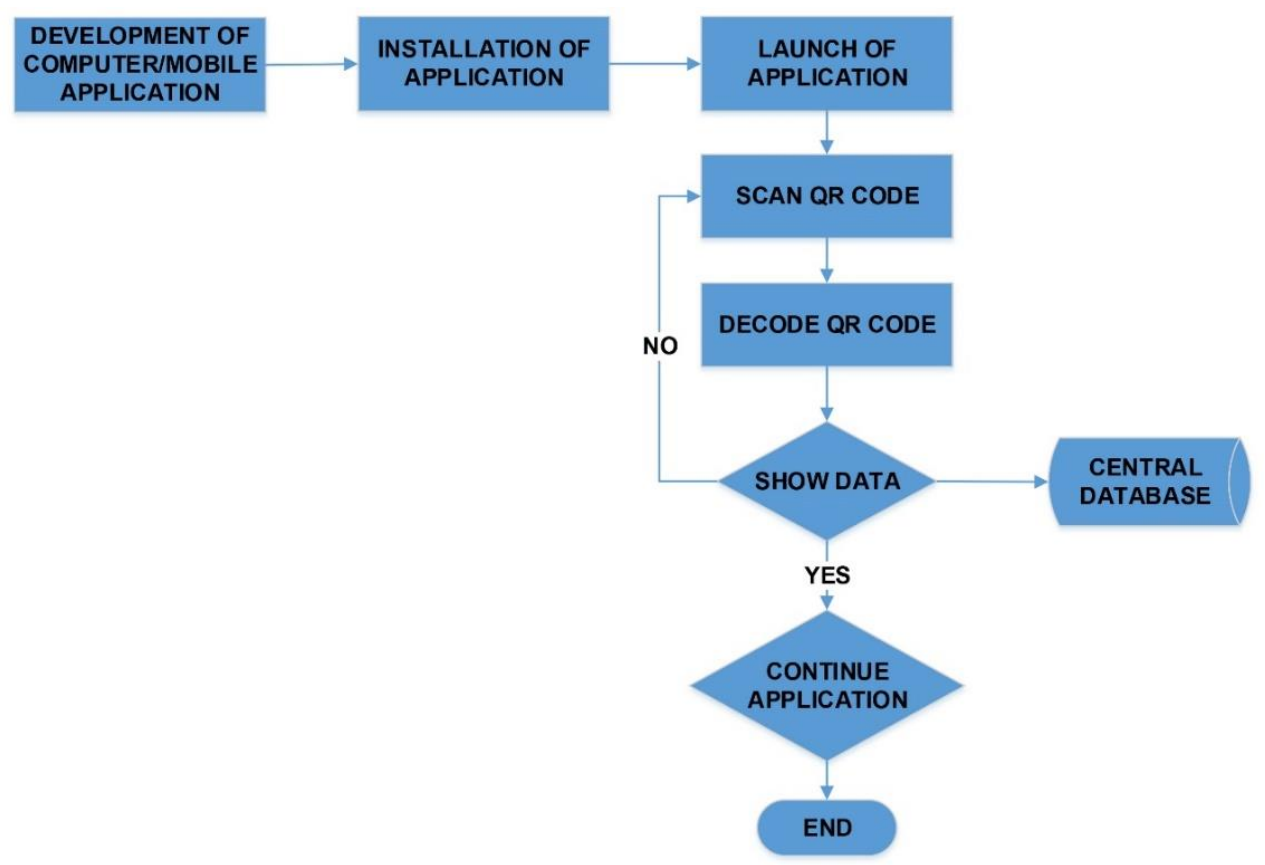

Figure 7 System for integrating QR codes in underground mining industry 


\section{RESULTS AND DISCUSSION}

\subsection{Application and Integration of $Q R$ codes in underground mining industry}

Three scenarios for application and integration of QR codes in underground mining industry will be presented in this paper:

1. Training video for setting up self-rescue apparatus in case of fire,

2. Identification of workers and their safety training,

3. Technical documentation of the equipment/machinery.

Below is an example of the three scenarios that was tested in the underground mine for lead and zinc "Sasa" in R. Macedonia.

\subsubsection{Training video for setting up self-rescue apparatus in case of fire}

Self-rescue unit is an apparatus that is used in the underground mining industry in case of emergency scenarios, like fires or release of toxic gases that contaminates breathable air in the surrounding atmosphere. These apparatuses are the first line of defense by providing oxygen in a closed breathing cycle, allowing personnel in emergency situations to facilitate their evacuation. History has shown that properly trained personnel will be more capable of utilizing this life support equipment.

In case of an emergency, the proper installation of the self-rescue apparatus is crucial for safe evacuation of all employees. By placing the QR code on each self-rescue apparatus, we can be sure that in case of an emergency situation, each employee, by simply scanning the $\mathrm{QR}$ code on his smartphone device, will receive a short video animation for the proper installation of the self-rescue apparatus and for its proper use. Figure 8 shows a QR code that is associated with a database where a short video animation is attached which describes the proper installation of the self-rescue apparatus. This key information is available by simply scanning the QR code with a smartphone device at any time and will simply display all the necessary information that is pre-installed in the database and associated with this crucial safety information. 


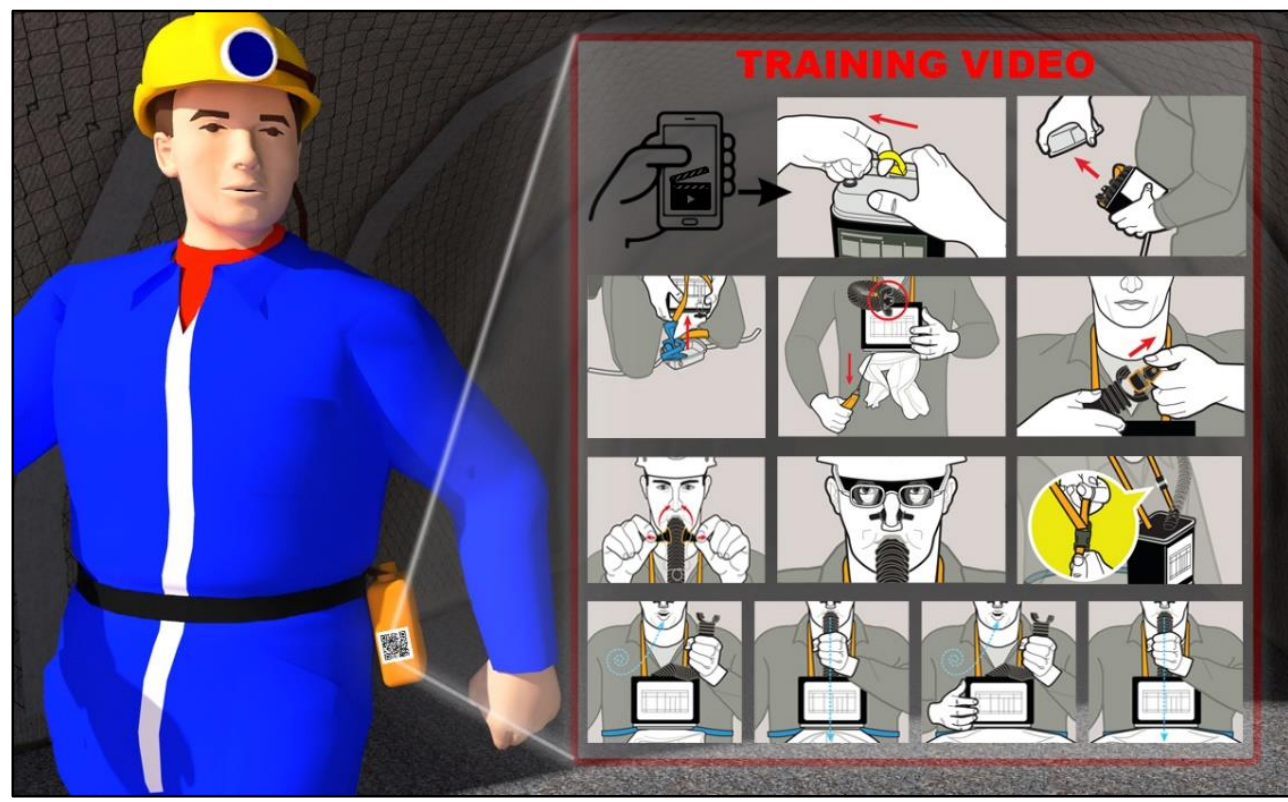

Figure 8 QR code that shows a training video for setting up a self-rescue apparatus in case of fire

\subsubsection{Identification of workers and their safety training}

Due to the specific working conditions in underground mines, it is of great importance for each supervisor to have available information about every worker, together with all data related to his expertise and safety training. By creating and uploading a personal profile in the database that contains all the necessary information about a worker, by simply scanning the QR code attached to his hard hat each supervisor can obtain data about the employee and, according to their expertise, deploy them to their respective jobs in the mine. The personal profile of the worker can contain several fields, from the level of their education to pronounced prohibitions for work with certain mechanization. Setting up this system can also save time for searching the information about workers through archives and getting the necessary information in just a few seconds. Figure 9 shows an example of identifying a worker with a list of his personal work profile and his certificates for safety training. 


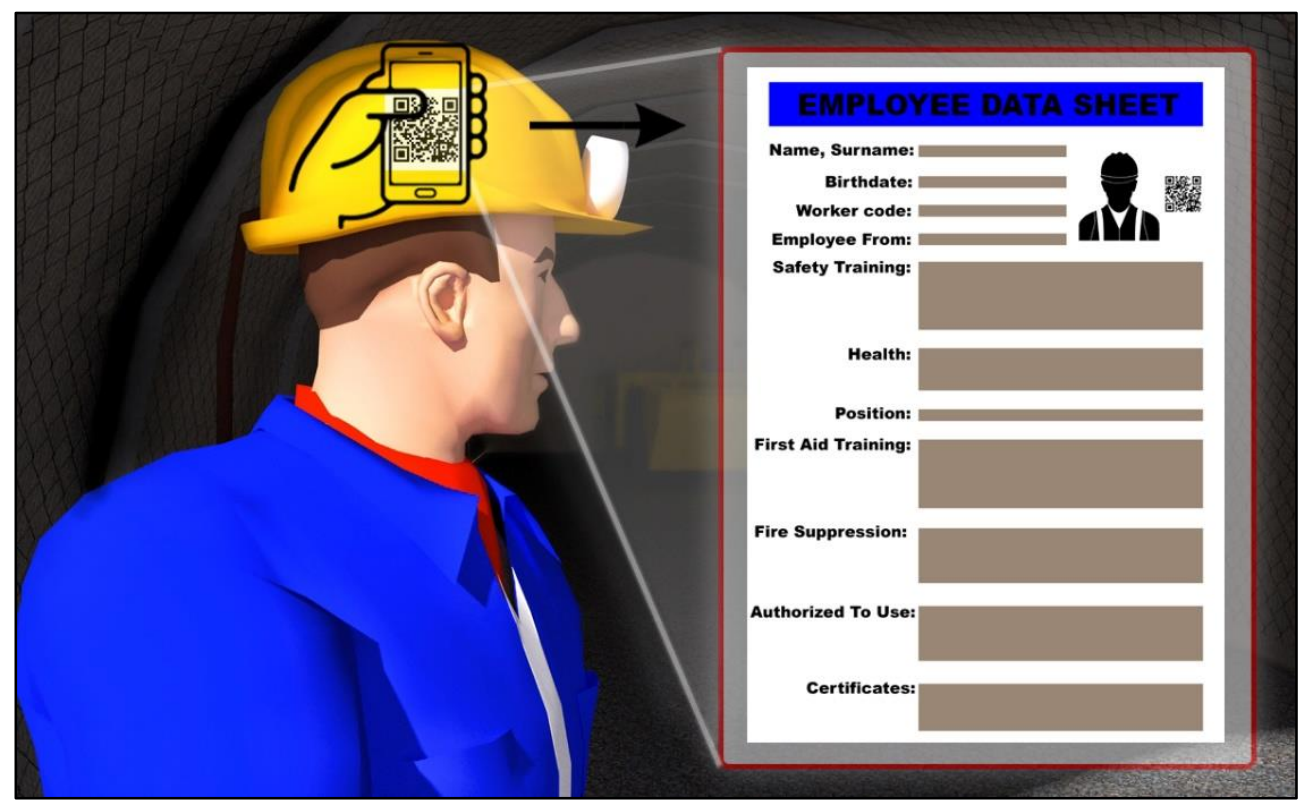

Figure $9 \mathrm{QR}$ code that shows a worker with a list of his personal work profile and his certificates for safety training

\subsubsection{Technical documentation of the equipment/machinery}

By placing $\mathrm{QR}$ codes on equipment/machinery, each worker can receive video demonstrations for safe work with the equipment/machinery and all the necessary technical documentation. With this system for instant retrieval of key information for every equipment/machinery, safety at work can be significantly increased and unwanted injuries can be avoided. This part of the system scenario can be extended to the section for obtaining documentation that will give a list of previous repairs and replacement of parts so that the profile of the equipment/machinery can be seen at any time. Figure 10 shows an example of a $\mathrm{QR}$ code that shows the technical documentation of the machinery. 


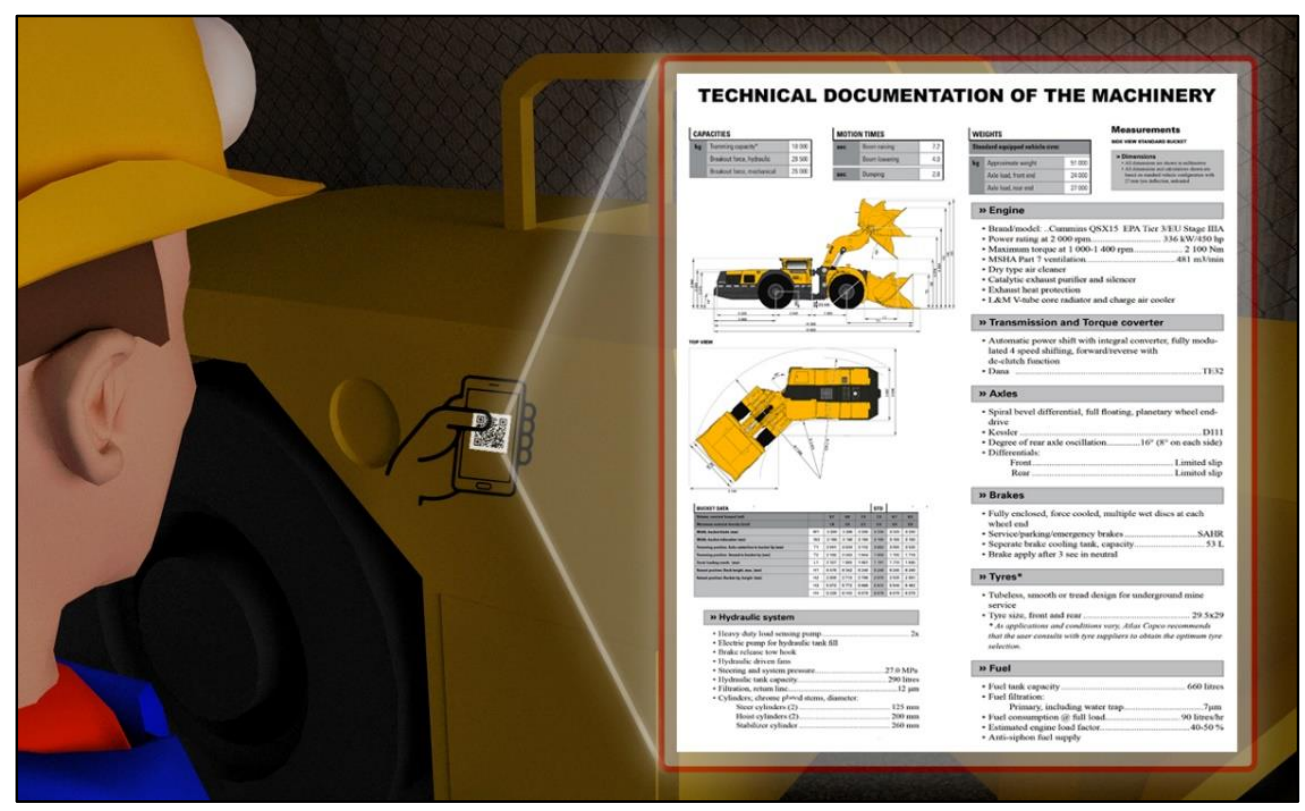

Figure 10 QR code that shows the technical documentation of the machinery

\section{CONCLUSION}

The development of the smartphone technology is spreading around the world at a very rapid pace and therefore there is a great demand for tools such as QR codes that can help users to get data and information in a much easier and faster way.

This paper presents a prototype model of QR code integration in underground mining industry using smartphones, as well as three scenarios for its application. The implementation of this system in the underground mining industry offers benefits in many areas:

- obtaining data and information that at a specific moment can be of crucial importance for safe execution of the given work activity,

- obtaining information in the form of video instructions. In this section, the QR codes have a wide range of implementation in the area of safety at work,

- obtaining information in the form of technical drawings for successful and accurate work operation according to all set standards,

- identification of each employee with an overview of the work profile, which can at any time provide information on the expertise of the employees so that they can be assigned to an appropriate work activity that corresponds to their expertise and prior preparation. 
The possibilities of implementing the system that can be installed in every mine proposed in this paper are enormous. This system offers improved work efficiency, better organization in operation activities, it increases work safety, etc. The uniqueness of this proposed system lies in its financial viability and easy adaptability to the existing IT infrastructure of any mine.

\section{REFERENCES}

CASE, A. et al. (2015) Accuracy of Smartphone Applications and Wearable Devices for Tracking Physical Activity Data. JAMA, 313(6), pp.625-626.

DEHLINGER, J. and DIXON, J. (2011) Mobile application software engineering: Challenges and research directions. Workshop on Mobile Software Engineering, 2, pp.17-25.

GU, X. and SUN, Z. K. (2013) Research on Artistic Treatment Methods for QR Codes. Applied Mechanics and Materials, 427, pp. 2134-2137.

LAURILA, J. and GATICA-PEREZ, D. (2012) The mobile data challenge: Big data for mobile computing research. Pervasive Computing, pp. 22-29.

LAW, C. and SO, S. (2010) QR codes in education. Journal of Educational Technology Development and Exchange, 3(1), pp. 85-100.

LORENZO, M. et al. (2014) BIM and QR-code. A Synergic Application in Construction Site Management. Procedia Engineering, 85, pp. 520-528.

MASALHA, F. and HIRZALLAH, N. (2014) A Students Attendance System Using QR Code. (IJACSA) International Journal of Advanced Computer Science and Applications, 5(30), pp.75-79.

OKAZAKI, S., NAVARRO, A. and CAMPO S. (2013) Cross-media integration of QR code: A preliminary exploration. Journal of Electronic Commerce Research, 14(2), pp.137-148.

PANDYA, K. and GALIYAWALA H. (2014) A Survey on QR Codes: in context of Research and Application. International Journal of Emerging Technology and Advanced Engineering, 4(3), pp. 258-262.

SCHOBEL, J., SCHICKLER, M. and PRYSS R. (2014) Towards process-driven mobile data collection applications: requirements, challenges, lessons learned. In: 10th Int'l Conference on Web Information Systems and Technologies (WEBIST 2014), Special Session on Business Apps, pp.371-382. 
SHARMA, A. and DHEERAJ, G. (2014) Smartphone as a real-time and participatory data collection tool for civil engineers. Int. J. Mod. Comput. Sci, 2(5), pp.22-27.

VAZQUEZ-BRISENO, M., NIETO-HIPOLITO, I. and JIMENEZ-GARCIA, E. (2010) Using QR Codes to Improve Mobile Wellness Applications. IJCSNS International Journal of Computer Science and Network Security, 10(12), pp. 50-55.

VONGPRADHIP, S. (2013) Use multiplexing to increase information in QR code. In: Computer Science \& Education (ICCSE), 8th International Conference, pp.102-110.

WAGNER, D., RICE, A. and BERESFORD A. (2014) Device Analyzer: Large-scale mobile data collection. ACM SIGMETRICS Performance Evaluation Review, 41(4), pp.53-56. 